\title{
Teresa Andrés Zamora (1907-1946): MEI el compromiso social y político como arma de cultura
} II, vol. 1

\author{
Romà Seguí i Francès \\ Jefe de Sección de Promoción Cultural \\ Institut Valencià de la Música \\ Generalitat Valenciana \\ segui_rom@gva.es
}

Recibido el 04-11-2010

Aceptado en $16-11-2010$

\section{Resumen}

La biografía de Teresa Andrés Zamora (Villalba de los Alcores, 1907- París, 1946) es un claro ejemplo de cómo el compromiso de una mujer republicana a través de la cultura se transformó en beligerancia política. Este artículo quiere mostrar una imagen de Teresa Andrés más profunda que la de una bibliotecaria que militó en el PCE, pretendiendo reconstruir su recorrido vital tanto en la faceta académica como profesional y política, con el objetivo de presentar una evolución que va desde su paso por la Residencia de Señoritas hasta su prematura muerte en París. Teresa Andrés Zamora representa una generación de mujeres republicanas que fue leal a la II República, trabajando incansablemente durante la Guerra Civil, y que padeció el exilio en una Francia ocupada.

\section{Palabras clave}

Guerra Civil (1936-1939); Andrés Zamora, Teresa; Gómez Nadal, Emili; Cuerpo Facultativo de Archivos, Bibliotecas y Museos; Residencia de Señoritas; Cultura Popular.

Teresa Andres Zamora (1907-1946) : social and political commitment as a weapon of culture

Abstract

The biography of Teresa Andrés Zamora (Villalba of Alcores, 1907 - Paris, 1946) is a clear example of how a Republican woman's commitment through culture was transformed into political militance. This article aims to show a deeper picture of Teresa Andrés than that of a librarian who was a member of the Spanish communist party (PCE), attempting to reconstruct the course of her academic, professional, and political life with the aim of presenting her evolution from her Residencia de Señoritas days to her untimely death in Paris. Teresa Andrés Zamora represents a generation of Republican women who were loyal to the Second Republic, worked tirelessly during the Civil War, and suffered exile in occupied France.

\section{Keywords}

Civil war (1936-1939); Andrés Zamora, Teresa; Gómez Nadal, Emili; Corps of Archives, Libraries and Museums; Residencia de Señoritas; Popular culture.

\section{INTRODUCCIÓN}

La Biblioteca Nacional de España en 2005 organizó una exposición, comisariada por Blanca Calvo y Ramón Salaberria, que se titulaba Biblioteca en guerra. Si bien no había sido el primer intento por rescatar las figuras que habían participado en la política bibliotecaria que se había llevado a cabo en el bando leal durante la última guerra civil española (1936-1939) ${ }^{1}$, se puede afirmar que fue la primera ocasión en la que se recuperó colectivamente a todo un grupo de bibliotecarios que padeció el

SEGUÍ I FRANCÉS, ROMÀ. “Teresa Andrés Zamora (1907-1946): el compromiso social y político como arma de cultura”. En: Métodos de información (MEI), II Época, Vol. 1, 2010, pp. 35-58.

DOI: en trámite. 
ominoso silencio de la posguerra franquista, ya fuera porque decidieron permanecer en España, soportando la relegación a la que fueron sometidos, ya fuera porque partieron para el exilio, sufriendo el olvido que impusieron los vencedores.

El caso de Teresa Andrés Zamora (Villalba de los Alcores, Valladolid, 1907 - París, 1946) se presenta quizá como el más paradigmático de todos. Tomás Navarro Tomás, Ramón Iglesia Parga, José Ignacio Mantecón o Juan Vicéns de la Llave habían figurado en la bio-bibliografía que con motivo del centenario del Cuerpo Facultativo de Archiveros, Bibliotecarios y Arqueólogos había elaborado Agustín Ruiz Cabriada (1958). Es cierto que en ningún momento aparece la palabra exilio para señalar la causa de por qué se encontraban fuera de España, aunque de una manera más o menos extensa se explicaba su actividad e incluso se alababan sus logros en países lejanos.

Lo que resulta llamativo es que no se incluyeran noticias biográficas de María Moliner y Teresa Andrés, las dos mujeres que habían trabajado más en el campo de la lectura pública durante el período bélico. María Moliner permaneció en España, fue relegada en la posguerra a no ocupar cargos de responsabilidad y logró destacar en un campo ajeno a la Biblioteconomía, el de la lexicografía, con su Diccionario de uso del español (1966), obviándose su esencial participación en la elaboración del Plan de Organización General de Bibliotecas del Estado, verdadero ejemplo de planificación bibliotecaria. Teresa Andrés, a diferencia de María Moliner, era militante del Partido Comunista de España (PCE) y partió para el exilio, muriendo a los treinta y nueve años en París. Su militancia supuso, con toda seguridad, una condición de peso para que se ocultase su figura y es uno de los obstáculos que no han permitido su estudio con la atención que se merece, ya que su compromiso político fue en demérito de su profesionalidad.

Sin embargo, el olvido que ha padecido Teresa Andrés tiene otras características que merecen ser destacadas, sobre todo porque denotan estrategias que indican la urgencia de investigar desde una perspectiva de género la actividad de las mujeres durante el período bélico y el posterior exilio. Por poner un ejemplo, su marido, Emili Gómez Nadal, ha generado bibliografía desde 1980, de tal suerte que ha sido objeto de sucesivas publicaciones, permitiendo su estudio a lo largo de todos estos años ${ }^{2}$, lo que pone de manifiesto, por un lado, el poco interés demostrado por nuestro colectivo profesional en la recuperación de su pasado y la discusión sobre problemas de contenido $\mathrm{y}$, por otro, la escasa comunicación entre diferentes grupos de investigadores, ya que el nombre y la obra de Teresa Andrés se encontraba explícito en más de un texto.

\subsection{La construcción de la biografía: metodología y alcance}

El objetivo del artículo ha sido el de presentar una biografía de Teresa Andrés desde la finalización de sus estudios universitarios hasta su muerte en París. Su elaboración ha concitado diversas dudas que se han intentado resolver mediante la consulta de los diferentes archivos en los que se podían encontrar datos sobre su trayectoria. Se partió de la hipótesis de que su carrera profesional había sido la que había vertebrado su biografía. Se ha podido constatar que la actividad de Teresa Andrés fue mucho más allá de la simple carrera profesional, lo que le hace valedora de estudios que reflejen 
de forma más pormenorizada tanto su faceta política -la que refleja su militancia en el PCE, la Unión General de Trabajadores (UGT) o el movimiento feminista- como su vertiente investigadora. Por otro lado, la visión de Teresa Andrés como bibliotecaria de la organización Cultura Popular ha sido la más estudiada hasta el momento, mereciendo un tratamiento diferenciado, puesto que la actividad que desarrolló en ésta proporciona suficientes datos como para elaborar otra investigación aparte. Por tanto, no se profundizará en este aspecto.

Se ha partido, pues, del momento en que Teresa Andrés decide ir a Madrid para realizar los cursos de doctorado, con el objetivo de redactar la tesis. A partir de ahí, se suceden diferentes experiencias que han sido estudiadas para comprender su evolución profesional y política.

\section{EL PERÍODO MADRILEÑO (1928-1936)}

\subsection{La Residencia de Señoritas y el Instituto-Escuela de Madrid}

Teresa Andrés nace en la población vallisoletana de Villalba de los Alcores. Fue la primogénita de una familia de seis hermanos. Su padre, Diógenes Andrés, era médico y su madre, Pilar Zamora, maestra. Al poco de nacer Teresa se trasladan a Cevico de la Torre (Palencia), donde ejercerían sus respectivas profesiones. Estudió el bachillerato en Palencia, obteniendo matrícula de honor en todas las asignaturas. Entre 1923 y 1927 estudió la carrera de Filosofía y Letras en Valladolid, presentándose por libre a la de Magisterio en Palencia, consiguiendo el premio extraordinario en la primera (AGA, 31/07017).

Nada más acabar la licenciatura Teresa Andrés se trasladó a Madrid con el objeto de obtener el grado de doctor, instalándose en la Residencia de Señoritas. Esta institución, dirigida desde su creación en 1915 por María de Maeztu, ofertaba dos tipos de actividades que son importantes para entender dos características esenciales de la biografiada. Por un lado, se ofrecían cursos de «lenguas vivas» -es decir, de alemán, inglés y francés- que impartían profesoras nativas. Se trataba de fomentar el aprendizaje de idiomas extranjeros en la misma institución. De hecho, Teresa Andrés llegó a dominar las tres lenguas, aunque sólo consta que se matriculó en ingles en los cursos 1929-1930 y 1930-1931 (FOYG. ARS, 11/4 y 11/6).

Por otro lado, se organizaban ciclos de conferencias a los que se invitaban a intelectuales de renombre. Los temas tratados eran muy diversos y pretendían satisfacer diferentes inquietudes, ya que la institución pretendía cultivar la cultura general de las matriculadas. Es interesante constatar que durante el curso 1928-1929 Clara Campoamor dio una conferencia titulada «Como crea la mujer el Derecho». El tema de la mujer en los ciclos de conferencias había sido un continuum desde el primer ciclo que se organizó durante el curso 1920-1921 (VÁZQUEZ, R., 2001, pp. 222-239). Además, es importante reseñar que en septiembre de 1928, debido a las gestiones de Clara Campoamor, se celebró en Madrid el Congreso Internacional de Mujeres Universitarias, acudiendo las representantes de la International Federation of University Woman. Varias de ellas se alojaron en la Residencia de Señoritas, en el Pabellón de Fortuny, 53, donde se encontraba Teresa Andrés. Es evidente que el 
compromiso feminista que Teresa Andrés asumió a lo largo de su vida se vio influenciado por toda una serie de factores que cristalizaron en la Residencia de Señoritas.

Durante los cursos de 1927-1928, 1928-1929 y mitad del de 1929-1930 Teresa Andrés da clases en la Sección de Letras de la Sección Preparatoria del InstitutoEscuela de Segunda Enseñanza de Madrid (AJAE 9-403). El trabajo fue compaginándolo con los estudios en la Universidad Central de Madrid. Durante los cursos 1928-1929 y 1929-1930 se examinó de las cuatro asignaturas que correspondían al ciclo de Doctorado (AUCM, GH/1-95). Durante el curso de doctorado de 1928-1929 conoce a Emili Gómez Nadal, quien será su marido.

\subsection{Las oposiciones al Cuerpo Facultativo de Archivos, Bibliotecas y Museos}

En algún momento del curso de 1929-1930 deja el contrato de profesora del Instituto-Escuela. Con toda seguridad, se sabía que iban a convocarse oposiciones al Cuerpo de Facultativo de Archivos, Bibliotecas y Museos y decidió preparárselas. Ya en una lista del curso 1929-1930 figura como una de las profesoras del InstitutoEscuela que está preparando oposiciones (FOYG, ARS 16/12).

En 1928 la Residencia de Señoritas renueva su convenio con el Instituto Internacional, formando una biblioteca inicial de unos doce mil volúmenes que se encontraba gestionada por bibliotecarias estadounidenses. Éstas, a parte de clasificar los títulos empleando la Dewey, imparten cursos de Biblioteconomía a las residentes y a personal externo. La encargada de organizarlo en el curso 1928-1929 fue Mauda Polley. Estos cursos, a tenor de los materiales elaborados por las propias alumnas, distaban mucho de la concepción bibliotecaria que imperaba por entonces entre los integrantes del Cuerpo Facultativo de Archivos, Bibliotecas y Museos, ya que incidían en cuestiones prácticas de catalogación y en el conocimiento de los tipos de servicios que debía ofrecer una bibliotecaria (RESIDENCIA DE SEÑORITAS, 1934). Las pruebas para las oposiciones del Cuerpo Facultativo estaban dirigidas a demostrar la erudición de los aspirantes con unos conocimientos que sólo eran aplicables en algunas instituciones públicas con fondos específicos. Hay constancia documental de que Teresa Andrés no solicitó plaza para ningún curso de Biblioteconomía. Es probable que conociera los objetivos que se perseguían con la oposición. No sería de extrañar que renunciase a los cursos por no adecuarse a sus intereses inmediatos.

El 8 de agosto de 1931 se resuelve de manera definitiva el expediente de las oposiciones de ingreso al Cuerpo de Facultativos de Archivos, Bibliotecas y Museos, en el que figura, como la aspirante que ha obtenido mayor puntuación, Teresa Andrés (AGA, 31/07017). La convocatoria, de 24 de noviembre de $1930^{3}$, publicitaba veinticinco plazas del mencionado Cuerpo y anunciaba que el Tribunal se constituiría en enero. La participación de las mujeres en esta convocatoria fue importante: de los veintiocho aspirantes dieciocho eran mujeres, ocupando además los siete primeros puestos.

El primer destino de Teresa Andrés fue la dirección del Museo Arqueológico de León. Toma posesión el 25 de agosto de 1931 y solicita dos días después un permiso de 
veinte días para descansar, ya que su salud se había resentido por los esfuerzos realizados para aprobar la oposición. Es obvio que el proceso selectivo se debió demorar más de lo habitual. La proclamación de la II República el 14 de abril había supuesto un trastorno para la Administración, generando con toda seguridad una serie de inconvenientes que no estaban previstos. El 31 de agosto se le concede el permiso y el 27 de septiembre se vuelve a incorporar a la citada plaza.

El 9 de septiembre de 1931 el director general de Bellas Artes, Ricardo de Orueta, inicia en un oficio la adscripción al Palacio Nacional -denominación republicana del Palacio Real de Madrid- de diferentes facultativos de Archivos, Bibliotecas y Museos. Por un lado, adscribe a la Biblioteca a Matilde López Serrano, Joaquín Moreno Villa y Leonardo Jesús Domínguez y Sánchez-Bordona, este último en calidad de jefe. Por otro, adscribe al Archivo a Victoria González Mateos, Pilar Plaza Arroyo y Teresa Andrés, también en calidad de jefa. Los seis facultativos estaban encargados de organizar y salvaguardar los fondos que contenía Palacio. Matilde López Serrano, Victoria González Mateos y Pilar Plaza Arroyo eran compañeras de oposición de Teresa Andrés.

El nombramiento supone un nuevo traslado a Madrid. No se conoce a ciencia cierta cuándo tomó posesión de la plaza en el Palacio $\mathrm{Nacional}^{4}$, aunque sí consta que la ocupa en su notificación de ascenso (de 5.000 pesetas anuales a 6.000) de fecha de 18 de octubre de 1932.

\subsection{La elaboración de la tesis doctoral y la relación con el Centro de Estudios Históricos}

El 19 de septiembre de 1932, poco más de un año de conseguir una plaza de facultativo, consigue un pensionado en el extranjero de la Junta de Ampliación de Estudios e Investigaciones Científicas por un período de once meses para matricularse en una universidad alemana. El 15 de septiembre de 1933 se reintegró a su destino del Palacio Nacional.

En el expediente que figura en la Junta de Ampliación de Estudios e Investigaciones Científicas se relacionan las asignaturas en las que se matriculó. Hay un acontecimiento histórico que durante su estancia debió marcarla para el resto de su vida: la ascensión de Hitler al poder en 1933. No sabemos cómo vivió los últimos días de la República de Weimar, el nombramiento de Hitler como canciller y la quema del Reichtag, aunque no sería de extrañar que la experiencia le empujase a comprometerse políticamente. De hecho, se desconoce la fecha de su ingreso en el PCE, puesto que no se conserva documentación que permita datarlo. No obstante, Alejandra Soler, que ingresó en 1934 en Valencia en el PCE, recordaba a Antonio Gómez Andrés, hijo de Teresa, que ya por esas fechas era conocida la militancia de la biografiada. Por tanto, es probable colegir que la experiencia alemana sería causa más que suficiente para su inicio en la militancia.

A instancias de Ramón Menéndez Pidal Teresa Andrés es reclamada el 9 de enero de 1935 para que acompañe a un grupo de estudiantes sudafricanos de la Universidad de Durban, ya que ella posee tanto conocimientos de Arte como de inglés. El 10 de enero 
se le concede el permiso para acompañar a los estudiantes en viaje de estudios.

El 14 de abril del mismo año Teresa Andrés presenta una instancia para solicitar un nuevo permiso. La Sección de Arqueología del Centro de Investigaciones Históricas la pensiona para que realice un viaje de estudios para hacer trabajos de investigación en las catedrales de Cuenca, Valencia, Barcelona y Zaragoza relativos a la rejería, tema de su tesis doctoral. El jefe de la Biblioteca de Palacio, Leonardo Jesús Domínguez y Sánchez-Bordona, se opuso a que se le diera este permiso, ya que, por un lado, había disfrutado de otro poco tiempo atrás y, por otro, el objeto de ambas licencias no revertía en el funcionamiento de la institución. Sin embargo, el 6 de mayo de 1935 empezó a disfrutar del permiso para realizar el viaje de estudios.

En octubre de 1935 empieza a disfrutar de una beca de la Sección de Arqueología Española del Centro de Estudios Históricos de la Junta de Ampliación de Estudios e Investigaciones Científicas. La beca finalizará en diciembre de 1936, en plena contienda.

La tesis versaba sobre la rejería española y hasta hace poco tiempo sólo se conocían las notas que Teresa Andrés fue acumulando a lo largo de su exilio. No obstante, poco antes de iniciarse la guerra, entregó un borrador definitivo de la tesis para que fuera leído por sus directores -Manuel Gómez Moreno y Elías Tormo-. Éste fue encontrado en la Unidad de Archivo y Documentación del CSIC a finales de 2009.

\section{EL INICIO DE LA GUERRA CIVIL (1936)}

La sublevación de julio de 1936 les sorprende a Teresa Andrés y a su hermano Troadio en Madrid. Gran parte de su familia -sus padres y sus hermanos Dionisio, Isabel, Mariano y Victoriano- se encontraba en Cevico de la Torre, zona que desde el inicio de la contienda fue controlada por los insurrectos. El 2 de septiembre serán fusilados su padre y su hermano Dionisio. Esta noticia no la conocerá hasta la llegada de su hermano Mariano a Valencia en 1937.

Los primeros meses de la contienda van a ser muy productivos. Organiza con Juan Vicéns de la Llave la Sección de Bibliotecas de Cultura Popular y empieza a integrarse en la estructura ministerial, primero de la mano de Ricardo de Orueta y después de la de Josep Renau. Se casa en octubre en Madrid con Emili Gómez Nadal. Su carrera profesional y su vida familiar van en ascenso.

\subsection{Cultura Popular}

Teresa Andrés es conocida sobre todo por ser la bibliotecaria que llevó adelante la Sección de Bibliotecas de Cultura Popular. La actividad que allí desarrolló, junto a Juan Vicéns de la Llave, fue ingente durante los primeros meses de la contienda. Como ya se ha señalado, sólo se tratarán algunos aspectos biográficos que son de relevancia para entender su futuro político y profesional ${ }^{5}$.

Cultura Popular fue una organización afín al PCE creada con el objetivo de coordinar las manifestaciones culturales que iban a realizar las organizaciones y los partidos que integraban el Frente Popular (ANDRÉS, T., 1937). Nació en abril de 1936 tras la 
victoria de las elecciones, constituyéndose un Comité Nacional en el que estaban representadas algunas organizaciones juveniles de partidos y sindicatos. Pero Cultura Popular adquirió relevancia tras el golpe de Estado de julio de 1936. En ese momento la organización incauta el palacio de los condes de Revillagigedo, en la calle Sacramento, $\mathrm{n}^{\circ}$ 1, una calle muy céntrica de Madrid, al lado del Ayuntamiento. Este será el domicilio de, entre otros, Teresa Andrés, Josep Renau, Antonio Deltoro y más tarde de Emili Gómez Nadal, siendo estos tres últimos colaboradores de la revista valenciana Nueva Cultura. Tomás García, quien tomaría las riendas de Cultura Popular tras Teresa Andrés, ya se encontraba trabajando en la organización (AZNAR, M. y PÉREZ I MORAGÓN, F., 2008, p. 397). Es importante hacer esta precisión, puesto que Teresa Andrés pasará a formar parte del equipo que trabajará con Josep Renau en el Ministerio de Instrucción Pública y Bellas Artes.

\subsection{El Comité de la Residencia de Señoritas}

El 21 de septiembre de 1936 se cesa a María de Maeztu como directora de la Residencia de Señoritas y se constituye un Comité presidido por Regina Lago y formado por Encarna Fuyola, Teresa Andrés y Ernestina González -en calidad de antiguas residentes- y Aurora Arnaiz, María Luisa Álvarez, Esperanza González, Pilar Coll y Laura Busca -en calidad de residentes-. Las tareas de secretaría recayeron en Esperanza González (ZULUETA, C. y MORENO, A., 1993, p. 235). El Comité tenía dos funciones claras: la depuración del personal y la administración de la institución.

Por aquel entonces en la Residencia había treinta residentes. En enero de 1937 éstas son evacuadas a la colonia escolar de Paiporta, gestionada por la FUE, y a finales de año una sección se instala en el edificio de la Casa de la Cultura de Valencia, calle de la Paz, no 42 (VÁZQUEZ, R., 2001, pp. 297-298).

\subsection{La Comisión Gestora del Cuerpo de Archiveros, Bibliotecarios y Arqueólogos}

Mediante el Decreto, de 5 de agosto de 1936, del Ministerio de Instrucción Pública y Bellas Artes, se creó la Comisión Gestora del Cuerpo de Facultativos de Archivos, Bibliotecas y Museos. Este órgano nacía con el objetivo «de que se realce en lo futuro la misión de cultura a que está destinado, para conseguir, sobre todo, que esa cultura sea puesta al servicio de las masas populares españolas».

La Comisión Gestora estaba compuesta por Tomás Navarro Tomás, en calidad de presidente, Juan Vicéns de la Llave, como secretario, y José Tudela de la Orden, Luisa Cuesta Gutiérrez, Teresa Andrés, Francisco Rocher Jordá, Ricardo Martínez Llorente y Ramón Iglesia Parga, como vocales. Es importante remarcar que Juan Vicéns de la Llave y Ramón Iglesia Parga militaban en el Partido Comunista, siendo el primero uno de los líderes de Cultura Popular. Sin embargo, hay que tener en cuenta que el director general de Bellas Artes por aquellas fechas era el historiador Ricardo de Orueta, quien pertenecía al Centro de Estudios Históricos de la Junta de 
Ampliación de Estudios e Investigaciones Científicas. Este dato es indispensable indicarlo para entender también el perfil de quienes constituían la Comisión Gestora, puesto que tanto Ramón Iglesia Parga, Teresa Andrés como Tomás Navarro Tomás eran personal de esta institución de investigación, compaginando este último el cargo de presidente de la Comisión Gestora con el de secretario de la Junta de Ampliación de Estudios.

La tarea encomendada a la Comisión Gestora en de Decreto de 5 de agosto era la de reorganizar el Cuerpo para que sirviera mejor a la cultura nacional. La Comisión Gestora no tardó en actuar y el 12 del mismo mes se publicó en la Gaceta una disposición del director general de Bellas Artes por la que se ordenaba que se pusiesen a disposición de la citada Comisión todos los miembros del Cuerpo. En estos primeros momentos de la guerra los trabajos de la Junta de Incautación y Protección del Tesoro Artístico requerían del concurso de los técnicos que sabían como organizar el patrimonio, de tal suerte que su labor era indispensable para plantear la salvaguarda del patrimonio artístico, bibliográfico y documental de manera ordenada.

Una de las confusiones que se ha generado acerca de la Comisión Gestora es su responsabilidad en la elaboración del Decreto de 9 de septiembre de 1936, mediante el que se cesaba a los facultativos de Archivos, Bibliotecas y Museos que no habían demostrado lealtad a la República. Esta función no consta en entre sus objetivos y las actas del órgano colegiado no recogen en ningún momento una actividad de este tipo, puesto que el Decreto de depuración había sido obra del ministro Jesús Hernández ${ }^{6}$.

El nombramiento de Josep Renau como director general de Bellas Artes en septiembre de 1936 debió suponer un impulso eficaz a los miembros que militaban en el PCE. No debe olvidarse que Josep Renau y Teresa Andrés habían convivido durante los primeros días de la contienda en el palacio de Revillagigedo, en la sede de Cultura Popular. Por tanto, se debería pensar en que existió una doble estrategia que propició el cambio de rumbo hacia un Consejo Central de Archivos, Bibliotecas y Tesoro Artístico, favorecida en esencia por tres miembros: Tomás Navarro Tomás, Vicéns de la Llave y Teresa Andrés. Josep Renau, por una parte, intentó controlar la actividad del personal del Cuerpo mediante disposiciones que permitiesen una gestión más eficaz, sustituyendo la Comisión Gestora por una Comisión Delegada y, por otro, creó un órgano político que planificase la política cultural dependiente de la Dirección General de Bellas Artes. De hecho, Josep Renau no dudó en firmar diferentes disposiciones, previas a la constitución del Consejo Central de Archivos, Bibliotecas y Tesoro Artístico, que iban encaminadas a un control exhaustivo de la actividad profesional de los miembros del Cuerpo en Madrid (CABAÑAS, M., 2007, p. 58-60).

El cambio de rumbo se propició el 12 de febrero de 1937 con la constitución de la Comisión Delegada del Consejo Central de Archivos, Bibliotecas y Tesoro Artístico. Esta substituía a la Comisión Gestora en sus tareas de controlar los movimientos del personal del Cuerpo, pero se creaba días antes del mismo Consejo Central de Archivos, Bibliotecas y Tesoro Artístico (PÉREZ BOYERO, E., 2005, p. 190-191). La Comisión Delegada la formaban, como presidente, José Tudela de la Orden y, como vocales, Rafael Lapesa, Antonio Martínez, Enrique Parés y Leonardo Baltanás 
(CABAÑAS, M., 2007, p. 245).

\section{VALENCIA, CAPITAL DE LA II REPÚBLICA (1937)}

Teresa Andrés se traslada definitivamente a Valencia en 1937 como consecuencia del traslado del Gobierno leal. No se conoce con exactitud la fecha en la que abandona Madrid, pero reside en febrero en la casa de la madre de Emili Gómez Nadal, Vicenta Nadal Alberola, justo encima de la de Nicolau Primitiu Gómez Serrano, su hermanastro, en la calle Gonzalo Juliá, $n^{\circ} 8$.

Su estancia en Valencia estará marcada por un episodio familiar que es indispensable explicar. El 16 de marzo de 1937 llega su hermano Mariano, quien había logrado pasar a las filas republicanas días antes. Durante la sublevación de julio, se encontraba en Cevico de la Torre (Palencia) con una parte de la familia Andrés. A finales del mismo mes, la guardia civil detuvo a su padre y a su hermano Dionisio, llevándoselos a la cárcel de Palencia. La causa de la detención, según la versión que circulaba entre los aldeanos, se basaba en una reyerta que hubo el 3 de mayo de 1936 entre unos falangistas de una pedanía de Villamuriel de Cerrato y unos vecinos de Cevico de la Torre, a consecuencia de la cual murió el falangista Máximo Inclán. Éste había sido apuñalado en el cuello y en el costado izquierdo, y se refugió en casa de un vecino de Cevico. Diógenes Andrés fue llamado para atenderle y cuando llegó había fallecido. Algunos de los vecinos consideraron que no le había atendido como debía y por ello había muerto (DE JUAN, A., 2005, P. 95). No obstante, parece que la causa fue la enemistad manifiesta entre el alcalde de Cevico y Diógenes Andrés. El alcalde pretendía que abandonase la plaza de médico para ofrecérsela a un otro de un pueblo cercano, que además era falangista. El 2 de septiembre los trasladaron a Villamuriel de Cerrato donde fueron fusilados al lado del cementerio junto a catorce personas, dos de ellas mujeres. A su vez, su madre es suspendida de empleo y sueldo como maestra.

Mariano, que había sido testigo de todo lo sucedido, fue incapaz de contárselo a su hermana. Nada más llegar a Valencia, le comunicó a Emili Gómez Nadal lo acontecido y decidieron esperar hasta encontrar la ocasión. A finales de marzo, un sábado, Teresa encontró una carta que había escrito Mariano a su hermano Troadio en la que le relataba lo sucedido. Mariano había salido esa mañana del cuartel y, cuando pasaba frente al Ministerio, le llamó un amigo de Teresa que le condujo hasta el café en el que se encontraba ella llorando? ${ }^{7}$.

\subsection{El Consejo Central de Archivos, Bibliotecas y Tesoro Artístico}

El nombramiento de Josep Renau en septiembre de 1936 como director general de Bellas Artes supuso un impulso a una política basada en la agitación cultural como medida de salvaguarda de la República. Tras su nombramiento se encuentra con una situación administrativa compleja que provenía de los primeros días de la sublevación. Por un lado, la Junta de Incautación y Protección del Tesoro Artístico desarrollaba las tareas de salvamento y salvaguarda del patrimonio, coordinándose con la Comisión Gestora del Cuerpo de Archiveros, Bibliotecarios y Museólogos, que era el brazo técnico sobre el que descansaba el impulso de los miembros de la Junta. Por otro, esta Comisión Gestora intentaba renovar los presupuestos sobre los que se había basado la profesión durante casi cincuenta años. Es evidente que la urgencia de los 
acontecimientos había provocado la actividad normativa, de tal forma que la coordinación se lograba mediante el esfuerzo colectivo. Josep Renau, mediante el Decreto de 16 de febrero de 1937, crea la Consejo Central de Archivos, Bibliotecas y Tesoro Artístico. Éste estaba formado por tres secciones: Archivos, Bibliotecas y Tesoro Artístico, siendo esta última la que asumía las funciones que venía desarrollando la Junta de Incautación y Protección del Tesoro Artístico. Cada una de las secciones tenía sus propios miembros, quienes se encargaban de llevar adelante las políticas culturales que se había fijado el Ministerio. En el caso de la Sección de Bibliotecas, presidía el órgano colegiado Tomás Navarro Tomás y constaba de las siguientes subsecciones: bibliotecas históricas, bibliotecas científicas, bibliotecas generales, bibliotecas generales y fomento bibliotecario, que se encontraban respectivamente coordinadas por Tomás Navarro Tomás, Benito Sánchez Alonso, Juan Vicéns de la Llave, María Moliner Ruiz y Teresa Andrés. Esta última ejercía las tareas de la secretaría. Es importante constatar que Tomás Navarro Tomás, Juan Vicéns de la Llave y Teresa Andrés ya habían formado parte de la Comisión Gestora del Cuerpo de Archivos, Bibliotecas y Museos. No obstante, no se debe olvidar que se integra en la Sección con un cargo de responsabilidad a María Moliner, la bibliotecaria que ejemplificaba los valores de las Misiones Pedagógicas, la que había hecho evolucionar los presupuestos del Patronato hasta conseguir la red de bibliotecas rurales en Valencia.

Es importante tener este punto en consideración, sobre todo porque será la Sección de Bibliotecas la que dará un respaldo definitivo a su Plan de Bibliotecas. Por tanto, la política de lectura pública fomentada por el Ministerio de Instrucción Pública comunista se basaba en buena medida en los hallazgos que se habían producido en la época de las Misiones Pedagógicas. No se trataba de rechazar los esfuerzos que ya habían realizado los anteriores gobiernos, sino de variar los objetivos básicos de la política bibliotecaria. Por eso, es necesario reconocer que la tarea que llevó a cabo la Sección de Bibliotecas del Consejo Central fue más allá de la mera ideología, porque se fundamentó en unos criterios profesionales que hoy en día nadie pondría en duda.

\subsubsection{La creación de bibliotecas en los institutos de enseñanza secundaria}

Una de las primeras medidas que se toma es la creación de bibliotecas en los institutos de enseñanza secundaria. Mediante Orden de 26 de febrero de 1937, el Ministerio de Instrucción Pública y Bellas Artes crea una biblioteca en cada uno de los institutos con la finalidad de fomentar la lectura y el estudio de los alumnos, imponiendo el préstamo domiciliario como uno de los objetivos ineludibles. Esta estrategia tenía como base la disponibilidad de muchos facultativos que habían perdido su puesto de trabajo, sobre todo como consecuencia del asedio a Madrid $^{8}$. La plantilla de funcionarios de la capital debía adscribirse a otros puestos de trabajo fuera de Madrid para poder continuar con su trabajo. Josep Renau, en una circular que data de 2 de marzo de 1937, instó a los facultativos, cuyos centros estaban cerrados, a solicitar la adscripción a una serie de establecimientos (APR. II/4389, 9.1). La lista resulta sorprendente. Por un lado, se proponían el Archivo Regional de Valencia --el hoy denominado Arxiu del Regne de València--, los archivos de las delegaciones de Hacienda de Barcelona, Cuenca, Girona, Guadalajara y Lleida, la Biblioteca Balaguer de Vilanova i la Geltrú y el Museo Arqueológico de Tarragona y, por otro, se 
relacionaban unos sesenta institutos de enseñanza secundaria en los que se había creado biblioteca $^{9}$. Esta medida contempla que la apertura de bibliotecas siempre se llevará a cabo con una dotación de personal especializado. Sin embargo, no todas las plazas se cubrieron debido a las reticencias creadas por parte del colectivo de Facultativos $^{10}$. Teresa Andrés, en el caso de Cataluña, recurrió a l'Escola de Bibliotecàries para que Jordi Rubió i Balaguer les propusiera diez candidatas (ESTIVILL, A., 1992, p. 355 y 385). Al final, sólo se pudo proveer una plaza.

\subsubsection{El curso de formación de los encargados de bibliotecas}

La necesidad de formación será uno de los temas recurrentes en las acciones que lleve a cabo la Sección de Bibliotecas del Consejo Central de Archivos, Bibliotecas y Museos. El ejemplo más relevante se encuentra en el Decreto, de 13 de noviembre de 1937, del Ministerio de Instrucción Pública y Sanidad, mediante el que se estructuran diferentes redes de bibliotecas públicas en todas las provincias. Se establecía una jerarquía que la lideraba la biblioteca provincial, de la que dependerían, sucesivamente, las comarcales, municipales y rurales. En los núcleos pequeños de población se instauraría una política de lotes renovables que dependería de las correspondientes bibliotecas municipales. La disposición también diseñaba una jerarquía profesional en la que aparecía una figura diferente a la del facultativo o el auxiliar: el encargado de la biblioteca. Éste trabajaría en las bibliotecas comarcales y estaría apoyado por la Oficina de Adquisición y Distribución de Libros y Cambio Internacional, organismo que se encargaría de la adquisición, envío y catalogación de los lotes.

Como consecuencia inmediata del Decreto, el Ministerio publica la Orden, de 30 de noviembre de 1937, mediante la que se convocaba un cursillo para la selección y formación de cincuenta plazas de encargados de biblioteca, que se celebraría en Valencia. Para acceder al cursillo, se debería superar una prueba en la que se tendría en cuenta los conocimientos de francés -una traducción con diccionario-, los de Historia, Literatura o Arte -debían desarrollar un tema por escrito- y los de cultura general -que se demostrarían en una entrevista con el tribunal-. El cursillo, que iba a durar tres meses, versaría sobre las siguientes materias: Historia -universal y española-, Literatura - universal y española-, Inglés, Bibliología, Biblioteconomía y Bibliografía. Es importante resaltar que se realizarían prácticas en bibliotecas y que la Bibliografía estaba orientada al uso de fuentes de información. Un programa parecido ya se había empleado en l'Escola de Bibliotecàries de Barcelona con éxito y Teresa Andrés intentó que ésta colaborara en la organización del cursillo, invitando a Jordi Rubió i Balaguer para que diese algunas de las conferencias y solicitando que le enviasen materiales de su Biblioteca (ESTIVILL, A., 1992, p. 298). Jordi Rubió no pudo desplazarse y l'Escola mandó publicaciones del centro y duplicados.

El Tribunal que debía encargarse de la selección del personal del cursillo y su desarrollo estaba integrado por Teresa Andrés, en calidad de presidenta, y Agustín Millares Carlo y María Moliner, como vocales. Las pruebas de selección se celebraron entre el 20 y 23 de enero de 1938 en Valencia y la prueba final el 22 de abril. 


\subsubsection{Las mejoras laborales del Cuerpo}

Uno de los aspectos más interesantes de la gestión de la Sección de Bibliotecas es sin duda la resolución de mejoras laborales para el Cuerpo. En un momento tan delicado como la guerra, la Sección de Bibliotecas logró solucionar dos reivindicaciones básicas: la subida de sueldo para los facultativos y auxiliares que cobraban menos de 6.000 pesetas anuales y la aprobación de la revisión de las plantillas de todos los establecimientos que dependían de la Sección.

La primera reivindicación se consiguió mediante una Orden publicada el 5 de octubre de 1937. La segunda, la revisión de las plantillas, fue gestionada a lo largo de 1937. Ambas reivindicaciones venían determinadas, con toda seguridad, por la militancia en el Sindicato de Trabajadores en Archivos, Bibliotecas y Museos de varios de los integrantes de la Sección de Bibliotecas ${ }^{11}$. Está documentada la pertenencia de Benito Sánchez Alonso en 1938 como secretario técnico de la delegación provincial del Sindicato en Madrid, aunque había ingresado en enero del mismo año (CDMH, PS Madrid, 801. Teresa Andrés era la presidenta de la Delegación de Valencia del Sindicato de Trabajadores en Archivos, Bibliotecas y Museos.

Estas mejoras laborales, sin ninguna duda, no se hubiesen podido plantear sin un reconocimiento previo de la tarea desarrollada por los profesionales, tanto en el ámbito de la defensa y salvaguarda del patrimonio como en el de la creación de nuevos establecimientos por toda la geografía republicana. El hecho de haber empleado la cultura como arma de propaganda había logrado elevar el estatus de todos los profesionales, puesto que la política bibliotecaria no había cesado en ningún momento de funcionar.

\subsection{La constitución del Sindicato de Trabajadores en Archivos, Bibliotecas y Museos}

Uno de los hechos más interesantes y menos estudiados es la creación del Sindicato de Trabajadores en Archivos, Bibliotecas y Museos en enero de 1937. Esta organización estaba integrada dentro de la Federación de Trabajadores de Enseñanza (FETE) de la UGT y agrupaba a todos aquellos individuos que efectuaran su labor en archivos, bibliotecas y museos, de tal suerte que entre los afiliados se encontraban subalternos, restauradores, mecanógrafos, facultativos, auxiliares o restauradores ${ }^{12}$. Es cierto que, aun desconociendo los estatutos, se puede reconstruir de una manera breve el recorrido de esta organización, teniendo en cuenta que la documentación que se ha podido consultar.

La idea de constituir un sindicato en el que estuviesen representados todos los trabajadores que actuaban en ese mundo comportaba el reconocimiento de una realidad fracasada. Las pruebas de selección para las plazas de Facultativos y Auxiliares de Archivos, Bibliotecas y Museos se habían basado en unos conocimientos eminentemente eruditos que no respondían a los presupuestos de la lectura pública ${ }^{13}$. De hecho, el curso de encargados de bibliotecas, cuya finalidad primordial era la de abastecer de personal el sistema de bibliotecas populares, se alejaba mucho de la concepción profesional que se perseguía en el Cuerpo. La enseñanza de técnicas dirigidas a unos cursillistas para gestionar de manera directa unos fondos con el 
objetivo de satisfacer a un público genérico chocaba con la tradición del Cuerpo. La escisión entre una estructura elitista que dirigía éstos con el ánimo de favorecer la investigación histórica en el mejor de los casos y otra que solucionaba los problemas cotidianos forzaba a generar una organización que tuviese en cuenta a todos los individuos que tomaban parte en el proceso de gestión de los archivos, bibliotecas y museos.

Se sabe que entre los facultativos se encontraban afiliados a la FETE desde el inicio de la II República, como es el caso de Luisa Cuesta. No se sabe a ciencia cierta los profesionales que ya estaban afiliados a la UGT, puesto que son pocas las fichas personales de los afiliados al Sindicato de Trabajadores de Archivos, Bibliotecas y Museos que se conservan y todas pertenecen a la delegación madrileña (CDMH, PSMadrid, 801). En ellas se indica un apartado en el que se señalaba la pertenencia a una organización política y sindical.

Por la documentación que se ha podido consultar, se sabe que el Sindicato de Trabajadores en Archivos, Bibliotecas y Museos llegó a tener tres delegaciones provinciales en Madrid, Valencia y Barcelona. Se sabía que la implicación que tuvo Teresa Andrés en éste era esencial, sobre todo por los testimonios indirectos que se habían podido conocer. Por otro lado, los Estatutos del Sindicato se desconocen, aunque por los oficios que se conservan se sabe que la estructura provincial partía de una jerarquía que se basaba en que la delegación que lideraba la acción sindical era la que se encontraba donde permanecía el Gobierno. Este dato no tiene por qué sorprender: la obligación de los profesionales que trabajaban en Madrid a desplazarse a otros destinos a principios de 1937 consiguió que la mayoría escogiese plazas en Valencia o Barcelona. Por tanto, la delegación más numerosa fue la de Valencia, donde se concentraron la mayoría de profesionales.

\subsubsection{Delegación de Valencia}

Mientras que de la Delegación de Madrid se conservan actas, de la de Valencia sólo podemos conocer su actividad de manera indirecta. Esta se encontraba situada en la calle Hernán Cortés, nº 19.

Hasta principios de marzo de 1938 presidía este Sindicato Provincial de Valencia Teresa Andrés, ocupando el cargo de secretario general Enrique Parés. Estos extremos son deducibles por dos documentos: una carta enviada por Carmela Iglesias a Lola Cañizares, de 24 de marzo de 1938, en la que lamenta que Teresa Andrés y Enrique Parés hayan sido trasladados a Barcelona (CDMH, PS-Madrid, 801-9, 19) y un oficio remitido desde Valencia a Madrid el 13 del mismo mes, en el que figura como presidente José $\mathrm{M}^{\mathrm{a}}$ Giner Pantoja y como secretaria adjunta Concha Zardoya (CDMH, PS-Madrid, 801-9, 18).

\section{EL TRASLADO DEL GOBIERNO REPUBLICANO A BARCELONA (1938- 1939) \\ El 31 de octubre de 1937 el Gobierno leal se traslada a Barcelona. Teresa Andrés es nombrada delegada del Ministerio de Instrucción Pública en Valencia ${ }^{14}$. Este cargo lo ocupará hasta principios de marzo, fecha en la que ya se encuentra en Barcelona. No}


abandona el cargo de secretaria de la Sección de Bibliotecas del Consejo Central de Archivos, Bibliotecas y Tesoro Artístico.

\subsection{El fin de la Sección de Bibliotecas}

El 6 de abril de 1938 se nombró Ministro de Instrucción Pública y Sanidad al anarquista Segundo Blanco. El cese del comunista Jesús Hernández Tomás no auguró nada bueno para las estructuras organizativas que se habían creado bajo su mandato. De hecho, fue el principio del fin de la Sección de Bibliotecas y del Plan de Bibliotecas de María Moliner ${ }^{15}$. Segundo Blanco rescató el Consejo Superior de Cultura mediante el Decreto de 7 de septiembre en el que relegaba la Sección de Bibliotecas a una ponencia que se titulaba Extensión de Cultura Popular. Aún así, la Sección de Bibliotecas continuó trabajando hasta el 19 de octubre de $1938^{16}$, fecha en la que se publicó la Orden de 17 del mismo mediante la que se suprimían los diferentes organismos y se cesaba a todos sus miembros. Para acabarlo de rematar, Segundo Blanco firma el 3 de diciembre una Orden por la que restablece la Sección de Archivos, Bibliotecas y Museos, que había sido creada durante la Dictadura de Primo de Rivera por el Real Decreto de 13 de septiembre de 1924.

\subsection{El viaje a Bélgica}

En julio de 1938, Teresa Andrés y Tomás Navarro Tomás viajan a Bélgica con motivo de la celebración de una reunión del Comité permanente de la IFLA, donde presenta una comunicación sobre la política bibliotecaria del Gobierno republicano (ANDRÉS, T., 1938). En ella explica los logros del Ministerio de Instrucción Pública y los de Cultura Popular, detallando la nueva estructura que había creado el Ministerio comunista.

En ese momento, se encuentra en avanzado estado de gestación de su primer hijo, Vicente. Un mes después, debido a los contactos que había establecido en Bélgica, vuelve allí para dar a luz, naciendo el 4 de septiembre ${ }^{17}$. A mediados de octubre vuelve a Barcelona, dejándolo en Bélgica a cargo de las Femmes Universitaires.

\subsection{Los últimos días de la guerra}

El 9 de octubre de 1938 quedó constituida en Barcelona el Sindicato Provincial de Trabajadores en Archivos, Bibliotecas y Museos. La Junta Directiva estaba presidida por Teresa Andrés y actuaba como secretario Enrique Parés (CDMH, PS-Madrid, 801-9, 29). Ella, según consta en su pasaporte, aún no había vuelto de su viaje a Bélgica. Ésta es una de las últimas noticias que tenemos de ella como bibliotecaria en España. En diciembre ya formaba parte de la sección de niños de la Comisión de Auxilio Femenino que presidía Dolores Ibarruri. En enero de $1939^{18}$ está trabajando en las labores editoriales para la preparación de la Exposición General de Nueva York, que se inauguraba el 30 de abril del mismo año, con motivo de la celebración del ciento cincuenta aniversario de la formación de Gobierno por George Washington y bajo el lema de la construcción del mundo de mañana. A finales de enero, huyen su marido y ella de Barcelona. 


\section{EL EXILIO (1939-1946)}

\subsection{Los primeros años del exilio (1939-1944)}

El 27 de febrero de 1939 Teresa Andrés cruza la frontera belga y se reúne con su hijo Vicente $^{19}$. Dirige el Hogar de Limelette para niños españoles en Walonia hasta diciembre de 1939, fecha en que cerró la institución después de repatriar a los niños acogidos. En ese momento, parten para París para reunirse con Emili Gómez Nadal.

\subsubsection{Servicio Español de Evacuación de Refugiados (SERE)}

En marzo de 1939 se funda en París el Servicio Español de Evacuación de Refugiados (SERE), organismo cercano al último primer ministro, Juan Negrín. Las personas que participaron en su gestión fueron Quiroga Pla, Juan Vicéns de la Llave, Emili Gómez Nadal y Juan Ignacio Mantecón. Emili Gómez Nadal formó parte de él como Jefe de Refugios en 1940 y su misión consistía en dar el visto bueno de las listas de evacuados. El jefe del SERE era Juan Ignacio Mantecón, otro facultativo de Archivos, Bibliotecas y Museos que acabó exiliándose en México y que había colaborado en Cultura Popular. Uno de los resultados evidentes de la gestión del SERE fue la evacuación de los facultativos militantes o simpatizantes del PCE como Juan Vicéns de la Llave o Juan Ignacio Mantecón. La actividad del SERE cesó en marzo de 1940 como consecuencia de las denuncias que recibía el Gobierno francés por tratarse de una organización comunista.

\subsubsection{El proyecto fallido de viaje a México}

Uno de los hechos que más sorprende es el fallido intento de emigración a Méjico que pretendía realizar el matrimonio Gómez Andrés en 1941. Emili Gómez Nadal era doctor en Historia y había sido becado por la Sección Hispanoamericana del Centro de Estudios Históricos, lo que implicaba posibilidades de trabajo en las universidades mexicanas. Por otro lado, los amigos y colegas bibliotecarios de Teresa Andrés habían logrado establecerse allí. El caso más significativo era el de Juan Vicéns de la Llave (SALABERRIA, R., 2002, p. 25-26). El 26 de mayo de 1941 Vicéns envía una carta al escritor Max Aub en la que le pide que se ponga en contacto con Teresa Andrés. Téngase en cuenta que todos ellos habían pertenecido al equipo nombrado por Josep Renau en la Dirección General de Bellas Artes. En la carta aparecen varios encargos de Vicéns a Aub, entre los que destaca el que atañe a Teresa Andrés:

Acabo de escribir a Teresa Andrés por un camino que hasta ahora ha salido bien, pero por si ahora no funciona y tú puedes comunicarte con ella, te ruego que le digas que inmediatamente se ha hecho lo que pide; que Puche [Álvarez] le va gestionar el visa[do] (aunque ahora son bastante difíciles de conseguir) y que los bibliotecarios han prometido hace tiempo pagarles el viaje a los tres. Que si recibís ahí aviso del visa y se lo avisáis, eso querrá decir también que tienen pagado el billete en New York y orden ahí de entregárselo para embarcar (AFMA Correspondencia, 28/1).

La carta de Vicéns es desesperada, puesto que en una cuartilla intenta explicar todo lo que se está intentando hacer por un grupo de exiliados españoles en un momento en 
el que ya ha comenzado la Guerra Mundial que se había anunciado. La amabilidad con la que habían sido recibidos los españoles en México por Lázaro Cárdenas contrastaba con los campos de concentración franceses. Pero los que habían podido sobrevivir al otro lado del océano no olvidaban a sus amigos en Francia.

La situación de matrimonio Gómez Andrés se podría haber calificado de privilegiada en 1940. Las gestiones que encomienda Teresa Andrés a Juan Vicéns de la Llave son evidentes: quería conseguir un visado para abandonar Francia. Ella estaba embarazada de su segundo hijo.

\subsubsection{La resistencia francesa (1940-1944)}

Sin embargo, no salieron de Francia y parece que el PCE fue la causa de esta permanencia. En junio de 1040, las tropas nazis ocuparon París. A finales del mismo año, el PCE reclama a Emili Gómez Nadal, que se encontraba con Teresa en Bayona, para reorganizarlo en la Francia ocupada. A partir de ese momento, el matrimonio Gómez Andrés se traslada a París y participa en tareas de organización de la resistencia francesa. Este episodio, que ha sido estudiado por Francesc Pérez i Moragón (2006) desde la óptica de Emili Gómez Nadal, no deja duda alguna sobre la responsabilidad de éste en las tareas relacionadas con la resistencia, sobre todo porque, y por poner un par de ejemplos, se dedicó a buscar integrantes de las Brigadas Internacionales para formar redes armadas o a ser responsable de propaganda del PCE.

Poca cosa se sabe de la implicación de Teresa Andrés en la resistencia. Es decir, no se ha encontrado documentación que explicite de manera fehaciente su colaboración. Se sabe que en 1942 envía a su primer hijo, Vicente, a España y que en 1943 hace lo mismo con el segundo, Antonio. Por lo que se trasluce de la correspondencia, durante ese tiempo se hace cargo del cuidado de sus hijos. Resulta extraño pensar que no se dedicase a ninguna otra actividad. Es verdad que en alguna necrológica de Teresa Andrés se indica que tomó parte en la resistencia en el cargo que le indicó el PCE, pero se desconoce cuál fue su cometido. Es evidente que debió cumplir con los objetivos que se le exigieron, puesto que tras la liberación de París tomó parte en actividades políticas y sindicales que requerían la confianza total del Partido.

El 22 de enero muere en Madrid su hijo Vicente de una meningitis. Es otro duro golpe para el matrimonio Gómez Andrés. El 1 de febrero de 1944 empieza a trabajar en la catalogación de los libros españoles que existían en las bibliotecas universitarias francesas. Marcel Bataillon, entonces director del Institut d'Estudes Hispaniques, le consigue este trabajo.

\subsection{De la liberación de París al compromiso político exclusivo (1944-1946)}

El 25 de agosto de 1944 se libera París. La novena compañía de la División Leclerc, formada en su mayoría por exiliados españoles, entraba en la capital francesa. La liberación de París suponía una gran victoria contra el fascismo, significaba el principio del fin de la Alemania nazi. Los españoles veían cercano el regreso, ya que la caída de Hitler implicaría la de Franco.

Poco tiempo después, se crea en París la Unión de Intelectuales Españoles, 
organización que intentaba agrupar a exiliados de diferentes procedencias políticas. El 1 de noviembre salió a la luz el primer número ciclostilado del Boletín de la Unión de Intelectuales Españoles. Emili Gómez Nadal está en el comité de redacción.

\subsubsection{La reconstrucción de la Federación Española de Trabajadores de la Enseñanza (FETE)}

El 17 de mayo de 1945 se constituye en París el Grupo de la FETE con el encargo de reconstruir la organización en tierras francesas. La Comisión Ejecutiva de la FETE se encontraba en México y envió unas instrucciones a Antonio Gardó. El Grupo lo formaban José Castro Escudero, Manuela Cabrera Sáez, Manuel González Asensio, Julio Hernández Ibáñez, Mateo Maculet Rodríguez, Emili Gómez Nadal, Teresa Andrés, José María Quiroga, José Giner Santonja, Guillermo Zúñiga, Julia Álvarez y Antonio Gardó. Poco después debió constituirse la Comisión Provisional de la FETE que estaba integrada por Julio Hernández, Teresa Andrés, Manuela Cabrera, Antonio Gardó y Josefa Uriz, quien no se encontraba en la lista del Grupo inicial de la FETE. Algunos de los nombres que aquí aparecen formaban parte de la Unión de Intelectuales Españoles. Cabe la pena resaltar la fuerte vinculación de Teresa Andrés al sindicato UGT, al que ya había estado afiliada durante la Guerra Civil, que se evidencia sobre todo en la asunción de responsabilidades estratégicas, en tanto que debe reconstruir la FETE tras la ocupación nazi.

No es el momento de analizar aquí la repercusión de las tareas encomendadas, puesto que la reconstrucción pasaba por realizar varios censos que afectaban tanto a los exiliados en tierras francesas como a los que habían padecido la represión franquista en España. Es decir, por un lado, intentaban recomponer los ficheros de los afiliados durante la República, recabando información sobre los trabajos que habían ejercido y sobre los cargos que habían desempeñado en la FETE, y por otro, se pedía que se informase sobre los compañeros que se encontraban en prisión en España -indicando el nombre del penal- y los que habían sido fusilados, solicitando que se facilitaran las direcciones de sus parientes. La solicitud de esta información, que implicaba la elaboración de un fichero personal completo, permite suponer que la tarea era ardua y que fue encomendada a personas solventes, de reconocido prestigio y total confianza (FPI. AARD, 285-17).

\subsubsection{La redacción del artículo «Las bibliotecas generales en España»}

El artículo más significativo de Teresa Andrés en esta época desde el punto de vista bibliotecario es el titulado «Las bibliotecas generales en España» (ANDRÉS, T., 1945). Lo escribió pensando en la España que dejaría Franco tras su posible derrocamiento por las potencias ganadoras de la Guerra Mundial. Por este motivo realizó un análisis previo sobre cómo había actuado Franco contra el sistema de lectura pública que se había intentado instaurar durante la II República y la guerra civil. Este análisis, a tenor de los últimos estudios que se han publicado sobre la actuación de las comisiones de depuración de la lectura (RUIZ BAUTISTA, E., 2005), se basaba en datos reales extraídos de los informes de éstas. El panorama, si cabe, era todavía más sombrío.

Lo que sorprende del artículo es el análisis desde la perspectiva de una España en paz. 
Por tanto desaparecen las menciones a organizaciones que habían dedicado sus esfuerzos a generar cultura en las trincheras, agitando mediante la alfabetización de los combatientes. La descripción que realiza se fundamenta en una planificación de un sistema estable heredero de los criterios biblioteconómicos que había perseguido en los últimos años (SEGUÍ, R., ,2007).

\subsubsection{La Unión de Mujeres Españolas y la celebración del Congreso de la Federación Internacional de Mujeres Demócratas (1945-1946)}

El 10 de mayo de 1945 Teresa Andrés se afilia a la Unión de Mujeres Españolas, una organización que había nacido en el seno del PCE. Éste es su último episodio público, que merece ser considerado desde diferentes perspectivas. Con la liberación de París, Teresa Andrés inicia una trayectoria de marcado carácter político. Si hasta la fecha, teniendo en cuenta su implicación en el Ministerio de Instrucción Pública y en el Sindicato de Trabajadores en Archivos, Bibliotecas y Museos, había ocupado cargos de cierta relevancia vinculados a su preparación técnica, tras la liberación se sumerge casi exclusivamente en tareas de organización en el ámbito sindical y en el de la reivindicación de los derechos de la mujer. Este último punto puede resultar sorprendente, ya que no figura como persona destacada de las agrupaciones de mujeres antifascistas durante la guerra -o, por lo menos, no se ha encontrado documentación que lo acredite-. No obstante, no se debe olvidar que estas agrupaciones postergaron sus reivindicaciones durante el conflicto con el objetivo de salvaguardar la II República, ya que la victoria era el fin básico de su lucha (NASH, M, 120-121). Y la derrota para las mujeres fue doble, porque perdieron una guerra y porque se anularon todos los derechos que habían conseguido en período republicano.

El caso de Teresa Andrés es paradigmático en este contexto, ya que no se podría entender su trayectoria -tanto desde el punto de vista profesional como académicosin el respaldo que supuso la política de emancipación de la mujer en la II República, puesto que ella pudo desarrollar su actividad basándose en esos logros. Por otro lado, su implicación en la defensa de los derechos de la mujer tiene unas características muy específicas en un contexto histórico muy determinado. Las exiliadas que habían sobrevivido a la ocupación nazi llevaban a sus espaldas dos guerras y, tras la celebración de la victoria de los aliados, creían que la vuelta a España era inminente. Franco había derogado todos los derechos que ellas habían adquirido tras años de lucha y no podía entenderse un retorno sin la restitución de éstos. Con la Constitución de 1932, la mujer había adquirido el mismo estatus jurídico que el varón. La pérdida de los derechos significaba un retroceso que ninguna mujer republicana estaba dispuesta a soportar, por lo menos en el colectivo de exiliadas.

A mediados de 1945, Teresa Andrés abandona su trabajo catalogando libros españoles para dedicarse de lleno en la organización del Congreso de la Federación Internacional de Mujeres Demócratas que iba a celebrarse en noviembre del mismo año en París. Su trabajo es el de secretaria ejecutiva. Antonio Gómez Andrés conserva documentación de todo tipo de esta época: informes sobre la situación de la mujer en España, tanto desde la perspectiva jurídica como social, sobre la disposición de paneles en una exposición, con el texto que éstos debían incluir, correspondencia con otras asociaciones de mujeres, recortes de prensa, etc. Lo esencial es entender que 
Teresa Andrés ya sobrepasa en este momento su condición de bibliotecaria para integrarse en un contexto ideológico que iba más allá de la defensa de los ideales republicanos. El compromiso político se había convertido en su única opción vital.

En marzo de 1946, Teresa Andrés viaja a Londres para presentar una ponencia sobre la lucha de la mujer española contra el franquismo en el International Woman's Day Committee (UNIÓN DE MUJERES ESPAÑOLAS, 1946). Su hermano Victoriano por esas fechas, cuando recibe unas fotos de Teresa, se alarma por su extrema delgadez. Ella achaca su estado de salud a la carga de trabajo que tiene encomendada, pero le diagnostican leucemia. El día 5 de julio de 1946 muere en el Hospital Cochin.

\section{CONCLUSIONES}

La vida de Teresa Andrés es lo suficientemente compleja como para requerir diferentes estudios que profundicen en diversos aspectos de su vida. Como se ha podido comprobar, su actividad alcanza ámbitos muy diferentes que deben tenerse en cuenta en el momento de analizar su trayectoria. Con este artículo, que refleja de manera sinóptica su biografía, se pretende reivindicar la figura de una bibliotecaria que supo implicarse en la política de la lectura pública. No se debe olvidar ni que su paso por la Residencia de Señoritas debió afianzar los ideales de la Institución Libre de Enseñanza -en tanto que tenía una fe inquebrantable en la formación- y el discurso feminista, ni que su militancia en el PCE le obligó a participar en los episodios que acontecieron en la Francia ocupada. Los exiliados que permanecieron en México fueron conscientes de el esfuerzo que supuso revivir de nuevo otra guerra contra el fascismo. De ahí surge un discurso combativo que deberá ser analizado en otros trabajos.

Por otro lado, resulta sintomático que no se haya empezado a trabajar de manera sistemática en la recuperación de las mujeres bibliotecarias de la época, sobre todo en la de aquellas que estuvieron casadas con maridos de renombre. Por poner un par de ejemplos, Josefina Callao se casó con Antoni $\mathrm{M}^{\mathrm{a}}$ Sbert y se sabe que tomo parte activa en la Junta de Auxilio a los Refugisdos Españoles; María Brey fue la mujer de Antonio Rodríguez-Moñino y dirigió la colección «Odres nuevos», a parte de llegar a trabajar en el Congreso de los Diputados. Deberíamos tomarnos más en serio las estrategias de ocultación y trabajar en reconstruir esa otra historia que aún no ha sido contada.

\footnotetext{
Notas

1. Hay tres trabajos anteriores que deben tenerse en cuenta: la recuperación de la figura de María Moliner realizada por Pilar Faus Sevilla (1990), la reconstrucción del período de guerra que hizo Luis García Ejarque (2000) y sobre todo el estudio introductorio de Ramón Salaberria que acompañó la traducción del libro L'Espange vivant... de Juan Vicéns de la Llave (2002).

2. Emili Gómez Nadal (València, 1907 - Valença d'Agen, 1993) perteneció al grupo de intelectuales valencianos que se agrupó en torno a la revista Nueva Cultura (1935-1937). Militó en las filas valencianistas y en las comunistas. En 1980 Manuel Aznar Soler y Francesc Pérez i Moragón se acercaron a Francia para realizarle una entrevista. El mismo año se publicó una pequeña parte de la entrevista. La transcripción completa de ésta se encuentra publicada como anexo en la edición que realizaron Antonio Gómez Andrés y Francesc Pérez i Moragón de los dietarios que se conservan de Emili Gómez Nadal (2008, pp. 369-413).

3. Para no ser en exceso prolijo en la cita de disposiciones legales, se ha incluido en la bibliografía un
} 
listado de todas las que han sido citadas en el artículo ordenadas cronológicamente.

4. Este es un asunto que no queda reflejado con claridad en su expediente personal, puesto que allí figura que Teresa Andrés se reincorpora el 27 de septiembre de 1931 a su plaza en León. Sin embargo, en el Archivo del Centro de Estudios Históricos, que se encuentra en el Consejo de Investigaciones Científicas, se conserva la correspondencia entre Teresa Andrés y Ricardo de Orueta correspondiente al período en que solicita los días de descanso y en ella figura la recepción del nombramiento en el Palacio Nacional. De hecho, en carta de 19 de septiembre de 1931 y coincidiendo con el descanso solicitado, Teresa Andrés agradece su nombramiento como jefa del Archivo del Palacio Nacional (ACSIC. UAYD, 1147/542). Es de suponer que su nombramiento tendría efectos a partir de una fecha posterior al 27 de septiembre.

5. Blanca Calvo, Alicia Girón y Ramón Salaberria han sido los artífices de la recuperación de la figura de Teresa Andrés. Elaboraron un dossier para la revista Educación y biblioteca (2005) que sirvió de orientación para reconstruir esa parte de nuestro pasado que aún está por estudiar.

6. No obstante, esta confusión es bastante generalizada. Antonio Rodríguez-Moñino la llama «Junta de depuración» (RODRÍGUEZ-MOÑINO, R., 2002, p. 67).

7. Mariano Andrés, que falleció en la Batalla del Ebro, redactó un dietario en el que contaba su estancia en Valencia. Esta documentación quedó en el piso de Vicenta Nadal, madre de Emili Gómez Nadal, quien murió en junio de 1940. Nicolau Primitiu Gómez Serrano conservó toda esta documentación, que hoy se encuentra depositada en la Biblioteca Valenciana, aunque aún no se ha procesado.

8. Josep Renau, en una circular de 19 de febrero de 1937 que envió a José Tudela de la Orden, como presidente de la Comisión Delegada y a escasos días de la constitución de ésta, se enumeraban los centros que se clausuraban en Madrid a causa del asedio que padecía. La lista es la siguiente: Archivo Histórico Nacional, Archivo del Palacio Nacional, Archivo de Protocolos, Biblioteca Nacional, las bibliotecas de la Universidad Central -excepción de la de la Facultad de Medicina «que cumple un servicio de guerra»-, de las escuelas de Industriales, Veterinaria, Bellas Artes y Superior de Arquitectura, del Conservatorio, del Museo de Ciencias Naturales, de las academias Española, de la Historia, de la Lengua y de Bellas Artes, del Centro de Estudios Históricos, de la Sociedad Económica Matritense, del Palacio Nacional y las bibliotecas populares de Madrid. Además, se cerraban los museos Arqueológico Nacional y el de Reproducciones Artísticas.

9. La lista de de institutos es la siguiente: Valencia -con cuatro centros-, Alzira, Gandia, Xàtiva, Requena, Alicante, Alcoi, Elx, Orihuela, Castelló, Barcelona -con seis centros-, Badalona, Manresa, Granollers, Igualada, Mataró, Terrassa, Vilafranca del Penedés, Vilanova i la Geltrú, Girona, Figueres, Olot, Sant Feliu de Guíxols, Lleida, Cervera, Tarragona, Reus, Tortosa, Mora de Ebro, Almería, Ciudad Real, Cuenca, Guádix, Jaén, Lorca, Manzanares, Murcia, Puerto Llano, Tomelloso, Valdepeñas, Villarrobledo, Alcázar de Cervantes, Avilés, Bilbao, Cangas de Onís, Cuevas de Almazora, Gijón, Guadalajara, Linares, Santander -dos centros-, Torrelavega, Baracaldo, Llanes, Portugalete, Quintanar de la Orden y Tarancón.

10. Las reticencias para cambiar de destino se plasmaron en prórrogas para la incorporación, excedencias por razones diversas, llegando incluso al cese (CABAÑAS, M., 2007, p. 245-246).

11. La revisión de plantilla al final no fue consignada en los presupuestos para el ejercicio de 1938. Se sabe que Tomás Navarro Tomás y Enrique Parés lograron que ésta se aceptara para los presupuestos de 1939, según consta en una circular del secretario de la Sección de Barcelona del Sindicato de Trabajadores en Archivos, Bibliotecas y Museos de 10 de octubre de 1938 (CDMH, PS-Madrid, 801/ 9, 29).

12. Es interesante comprobar este hecho mediante la consulta de las fichas de afiliados de la Delegación Provincial del Sindicato de Madrid. (CDMH. PS Madrid, 801)

13. Es cierto que en 1932 se establecieron nuevas normas para la realización de las pruebas selectivas para entrar en el Cuerpo. No obstante, éstas tampoco satisfacían el ámbito de la lectura pública (TORREBLANCA, A., 2008, pp. 112-116).

14. Se han encontrado referencias diversas que señalan el nombramiento, pero no se ha podido constatar mediante un nombramiento o una circular que lo anuncie.

15. A esta conclusión también llega Luis García Ejarque (2000, p. 253), persona que no puede tildarse de filocomunista.

16. Por ejemplo, hay una circular firmada por Teresa Andrés el 6 de junio de 1838 dirigida a Justo García Soriano en la que se indica que el cargo es accidental (AMO. LJGS, 988).

17. Antonio Gómez Andrés conserva el pasaporte de su madre, figurando allí todos los visados. 
18. Esta noticia se conoce por una carta de 01.01.1939 de Emili Gómez Nadal a Nicolau Primitiu Gómez Serrano que se encuentra en la Biblioteca Valenciana. Este fondo, como antes se ha explicado, está sin procesar.

19. La mayoría de los datos que se ofrecen en este apartado están entresacados de la documentación que conserva Antonio Gómez Andrés. En caso contrario, se indicará la fuente o el archivo.

\section{Referencias bibliográficas}

ANDRÉS, T. (1937): «Cultura Popular y su Sección de Bibliotecas». Tierra firme (1936), año II, nº 3-4, pp. 604-606.

ANDRÉS, T. (1938): «Les bibliothèques populaires en Espagne pendant la guerre» en: Actes du Comité International des Bibliothèques. 11 me session. Nijhoff, La Haye, pp. 107-109.

ANDRÉS, T. (1945): «Las bibliotecas generales en España». Boletín de la Unión de Intelectuales Españoles. Año II, nº 4, marzo, pp. 4-5.

AZNAR, M. (2007): «La Casa de la Cultura de València» en: València, capital cutural de la República (1936-1937). Consell Valencià de Cultura, València, v. I, pp. 131-154.

AZNAR, M. (2008): «La política cultural del Ministerio de Instrucción Pública y Bellas Artes (19361937)» en: En defensa de la cultura: Valencia, capital de la República (1936-1937). Universitat de València, València, pp. 42-63.

AZNAR, M. y PÉREZ I MORAGÓN, F. (2008): «Entrevista a Emili Gómez Nadal» en: GÓMEZ NADAL, Emili: Diaris i records. Universitat de València, València, pp. 369-413.

BIBLIOTECA (2005): Biblioteca en guerra. Biblioteca Nacional de España, Madrid.

BOLAÑOS, C. (1998): «El “procedimiento” contra Agustín Millares Carlo en el Tribunal Especial para la represión de la Masonería y el Comunismo». Boletín Millares Carlo, nº 16, pp. 11-20.

CALVO, B.(2005): «Viaje en busca de un tesoro: Teresa Andrés Zamora». Educación y biblioteca, $\mathrm{n}^{\circ}$ 145, enero-febrero, pp. 72-78.

CABAÑAS, M. (2007): Josep Renau: arte y propaganda en guerra. Ministerio de Cultura, Madrid.

DE JUAN, A.(2005): Los médicos de la otra orilla. Cálamo, Palencia.

ESTIVILL, A. (1992): L’Escola de Bibliotecàries (1915-1939). Diputació de Barcelona, Barcelona.

FAUS, P. (1990): La lectura pública en España y el Plan de Bibliotecas de María Moliner. ANABAD, Madrid.

GARCÍA EJARQUE , L. (2000): Historia de la lectura pública en España. Trea, Gijón.

GÓMEZ NADAL, E. (2008): Diaris i records. Universitat de València, València.

GÓMEZ SERRANO, NP. (2010): Dietaris 1936. Biblioteca Valenciana, Valencia.

MINISTERIO DE INSTRUCCIÓN PÚBLICA (1938): Un año de trabajo en la Sección de Bibliotecas (marzo 1937-abril 1938). Ministerio de Instrucción Pública, Barcelona.

NASH, M. (2006): Rojas: las mujeres republicanas en la Guerra Civil. $5^{\circ}$ ed. Taurus, Madrid.

PÉREZ BOYERO, E. (2005): «El archivo de la Biblioteca Nacional: fuentes documentales para el estudio de los archivos, bibliotecas y museos españoles durante la guerra civil» en: Biblioteca en guerra. 
Biblioteca Nacional de España, Madrid, pp. 169-195.

PÉREZ I MORAGÓN, F. (2006): «Emili Gómez Nadal» em Nicolau Primitiu i la Guerra Civil. Biblioteca Valenciana, València, pp. 159-182.

RESIDENCIA DE SEÑORITAS (1934): Reglas de catalogación. Residencia de Señoritas, Madrid.

RODRÍGUEZ-MOÑINO, R. (2002): La vida y obra del bibliófilo y bibliógrafo extremeño D. Antonio Rodríguez-Moñino. $2^{\mathrm{a}}$ ed. Beturia, Madrid.

RUIZ BAUTISTA, E (2005): Los señores del libro: propagandistas, censores y bibliotecarios en el primer franquismo. Trea, Gijón.

RUIZ CABRIADA, A. (1958): Bio-bibliografía del Cuerpo Facultativo de Archiveros, Bibliotecarios y Arqueólogos: 1858-1958. Junta Técnica de Archivos, Bibliotecas y Museos, Madrid.

SALABERRIA, R. (2002): «La larga marcha de Juan Vicéns (Zaragoza,1895 - Pekín,1959)» en: VICÉNS DE LA LLAVE, J.: España viva: el pueblo a la conquista de la cultura. Vosa, Asociación Educación y Bibliotecas, Madrid, pp. 7-30.

SALABERRIA, R., CALVO, B. y GIRÓN, A. (2005): «Donde nunca llega el sol: reconstrucción arqueológica de Teresa Andrés, bibliotecaria comunista». Educación y biblioteca, n ${ }^{\circ}$ 145, enero-febrero, pp. 79-89.

SEGUÍ, R. (2007): «Les reflexions de Teresa Andrés sobre el nou sistema bibliotecari espanyol: de l'autocrítica a les iniciatives realistes». Laberintos: revista de estudios sobre los exilios culturales españoles, $\mathrm{n}^{\circ}$ 8-9, pp. 74-92.

TORREBLANCA, A. (2008): «El acceso al Cuerpo» en: Sic vos non vobis: 150 años de archiveros y bibliotecarios. Biblioteca Nacional, Madrid, pp. 89-149.

UNIÓN DE MUJERES ESPAÑOLAS (1946): «Teresa Andrés en Londres». Unión de Mujeres: boletín interior, $\mathrm{n}^{\circ}$ 6, 25/05/1946, pp. 2.

VÁZQUEZ, R. (2001): La Institución Libre de Enseñanza y la educación de la mujer en España: la Residencia de Señoritas (1915-1936). R. Vázquez, A Coruña.

ZULUETA, C. de y MORENO, A. (1993): Ni convento ni college: la Residencia de Señoritas. Publicaciones de la Residencia de Estudiantes, Madrid.

\section{Disposiciones legales:}

MINISTERIO DE INSTRUCCIÓN PÚBLICA Y BELLAS ARTES: Real orden, de 24 de noviembre de 1930, (rectificada) disponiendo se anuncie a oposición 25 plazas destinadas a formar la lista de aspirantes para cubrir las vacantes que existan en la última categoría del Cuerpo facultativo de Archiveros, Bibliotecarios y Arqueólogos. Gaceta de Madrid, nº 331, de 27/11/1930, pp. 1222-1224.

MINISTERIO DE INSTRUCCIÓN PÚBLICA Y BELLAS ARTES: Orden, de 21 de septiembre de 1936, admitiendo la dimisión del cargo de Directora de la Residencia de Señoritas, de Madrid, a doña María Maeztu Withney. Gaceta de Madrid: Diario Oficial de la República, nº266, de 22/09/1936, pp. 1917.

MINISTERIO DE INSTRUCCIÓN PÚBLICA Y BELLAS ARTES: Orden, de 21 de septiembre de 1936, creando, en la forma que se indica, un Comité en la Residencia de Señoritas, de Madrid. Gaceta de Madrid: Diario Oficial de la República, nº 266, de 22/09/1936, pp. 1917. 
MINISTERIO DE INSTRUCCIÓN PÚBLICA Y BELLAS ARTES: Decreto, de 23 de julio de 1936, disponiendo se constituya un Junta, en relación inmediata con el Director general de Bellas Artes, encargada de intervenir con amplias facultades cuantos objetos de arte o históricos y científicos se encuentren en los Palacios ocupados. Gaceta de Madrid: Diario Oficial de la República, $\mathrm{n}^{\circ}$ 207, de 25/07/1936, pp. 834.

MINISTERIO DE INSTRUCCIÓN PÚBLICA Y BELLAS ARTES: Decreto, de 1 de agosto de 1936, disponiendo que la Junta creada por Decreto de 23 de Julio del presente año se denominará de Incautación y Protección del Patrimonio Artístico. Gaceta de Madrid: Diario Oficial de la República, n ${ }^{\circ}$ 215, de 02/08/1936, pp. 999.

MINISTERIO DE INSTRUCCIÓN PÚBLICA Y BELLAS ARTES: Decreto, de 5 de agosto de 1936, disponiendo cese en sus funciones la Junta facultativa del Cuerpo de Archiveros, Bibliotecarios y Arqueólogos, alcanzando el cese a los Vocales natos y electivos y a los actuales Inspectores técnicos, y considerando suprimido, desapareciendo sus funciones, el Consejo asesor de dicho Cuerpo, y nombrando para sustituir a la extinguida Junta facultativa y a los Inspectores técnicos una Comisión gestora integrada en la forma que se expresa. Gaceta de Madrid: Diario Oficial de la República, $\mathrm{n}^{\circ}$ 219, de 06/08/1936, pp. 1086.

MINISTERIO DE INSTRUCCIÓN PÚBLICA Y BELLAS ARTES. DIRECCIÓN GENERAL DE BELLAS ARTES: Orden, de 10 de agosto de 1936, disponiendo que todos los funcionarios del Cuerpo facultativo de Archivos, Bibliotecas y Museos, tanto facultativos como auxiliares, destinados en Madrid, se pongan inmediatamente a disposición de la Comisión gestora de Archivos, Bibliotecas y Museos. Gaceta de Madrid: Diario Oficial de la República, nº 225, de 12/08/1936, pp. 1220.

MINISTERIO DE INSTRUCCIÓN PÚBLICA Y BELLAS ARTES: Decreto, de 9 de septiembre de 1936, disponiendo la cesantía de los funcionarios facultativos del Cuerpo de Archiveros, Bibliotecarios y Arqueólogos que se mencionan. Gaceta de Madrid: Diario Oficial de la República, $\mathrm{n}^{\circ}$ 254, de 10/09/1936, pp.1730.

MINISTERIO DE INSTRUCCIÓN PÚBLICA Y BELLAS ARTES. DIRECCIÓN GENERAL DE BELLAS ARTES: Orden, de 5 de octubre de 1936, disponiendo que cuantos funcionarios de toda índole presten sus servicios en cualquiera de las dependencias oficiales domiciliadas en el edificio de la Biblioteca y Museos Nacionales se presenten diariamente en la Sección de Archivos de este Ministerio, firmando la oportuna comparecencia. Gaceta de Madrid: Diario Oficial de la República, no 283, de 09/10/1936, pp. 271.

MINISTERIO DE INSTRUCCIÓN PÚBLICA Y BELLAS ARTES: Decreto, de 16 de febrero de 1937, creando un Consejo Central de Archivos, Bibliotecas y Tesoro Artístico con los fines que se expresan. Gaceta de la República: Diario Oficial, nº 48, de 17/02/1937, pp. 847-848.

MINISTERIO DE INSTRUCCIÓN PÚBLICA Y BELLAS ARTES: Orden, de 26 de febrero de 1937, disponiendo que en los Institutos de Segunda Enseñanza funcione una biblioteca a cargo de los funcionarios del Cuerpo facultativo de Archiveros, Bibliotecarios y Arqueólogos, que serán designados por este Ministerio y con los fines que se expresan. Gaceta de la República: Diario Oficial, nº 63 , de 04/03/1937, pp. 1057-1058.

MINISTERIO DE INSTRUCCIÓN PÚBLICA Y BELLAS ARTES: Orden, de 5 de abril de 1937, creando la Junta Central del Tesoro Artístico, dependiente del Consejo Central de Archivos, Bibliotecas y Tesoro Artístico, y cuyas facultades y misión a realizar se establecen. Gaceta de la República: Diario Oficial, nº 109, de 19/04/1937, pp. 282-283.

MINISTERIO DE INSTRUCCIÓN PÚBLICA Y BELLAS ARTES: Orden, de 5 de abril de 1937, señalando las atribuciones y actividades del Consejo Central de Archivos, Bibliotecas y Tesoro Artístico, creado por Decreto-ley de 16 de Febrero último. Gaceta de la República: Diario Oficial, $\mathrm{n}^{\circ}$ 109, de 19/04/1937, pp. 282. 
MINISTERIO DE INSTRUCCIÓN PÚBLICA Y SANIDAD:Orden, de 28 de mayo de 1937, disponiendo pasen a depender del Consejo Central de Archivos, Bibliotecas y Tesoro Artístico todas las bibliotecas creadas por el Patronato de Misiones Pedagógicas. Gaceta de la República: Diario Oficial, $\mathrm{n}^{\mathrm{o}}$ 152, de 01/06/1937, pp. 1030.

MINISTERIO DE INSTRUCCIÓN PÚBLICA Y SANIDAD: Orden, de 28 de septiembre 1937, disponiendo que todos los funcionarios de los Cuerpos Facultativo y Auxiliar de Archiveros, Bibliotecarios y Arqueólogos que actualmente están prestando servicio en los centros dependientes de este Ministerio que funcionan en la zona sometida al poder legítimo de la República, y que no perciban sueldos superiores a 6.000 pesetas, disfruten durante el persente año de una gratificación de 1.000 pesetas. Gaceta de la República: Diario Oficial, $\mathrm{n}^{\circ}$ 278, de 05/10/1937, pp. 59.

MINISTERIO DE INSTRUCCIÓN PÚBLICA Y SANIDAD: Decreto, de 13 de noviembre de 1937, creando en cada capital de provincia una Biblioteca general con la denominación de Biblioteca provincial con los fines y facultades que se establecen, de conformidad con el articulo que se inserta. Gaceta de la República: Diario Oficial, nº 318, de 14/11/1937, pp. 540-541.

MINISTERIO DE INSTRUCCIÓN PÚBLICA Y SANIDAD: Orden, de 30 de noviembre de 1937, convocando un cursillo de selección y formación de cincuenta encargados de Bibliotecas en las condiciones que se establecen. Gaceta de la República: Diario Oficial, nº 338, de 04/12/1937, pp. 905.

MINISTERIO DE INSTRUCCIÓN PÚBLICA Y SANIDAD: Orden, de 7 de enero de 1938, designando el Tribunal que ha de juzgar y dirigir el cursillo convocado para la selección y formación de cincuenta Encargados de Bibliotecas. Gaceta de la República: Diario Oficial, nº 13, de 13/01/1938, pp. 187.

MINISTERIO DE INSTRUCCIÓN PÚBLICA Y SANIDAD: Decreto fijando temporalmente en Barcelona la residencia oficial del Gobierno de la República, a partir de esta fecha. Gaceta de la República: Diario Oficial, no 304, de 31/10/1937, pp. 392.

MINISTERIO DE INSTRUCCIÓN PÚBLICA Y SANIDAD: Decreto, de 7 de septiembre de 1938, creando un Consejo Superior de Cultura de la República, que enlace y reúna en si mismo los múltiples organismos que independientemente se ocupen de tan fundamental problema como es el de la cultura nacional dependiente del Ministerio de Instrucción Pública y Sanidad y que tendrá atribuciones que en este Decreto se le asignan. Gaceta de la República: Diario Oficial, nº 251, de 08/09/1938, pp. 1129-1131.

MINISTERIO DE INSTRUCCIÓN PÚBLICA Y SANIDAD: Orden, de 17 de octubre de 1938, dictando normas para que el Consejo Superior de Cultura de la República pueda desarrollar la labor que corresponde a su denominación. Gaceta de la República: Diario Oficial, nº 292, de 19/10/1938, pp. 230 .

MINISTERIO DE INSTRUCCIÓN PÚBLICA Y SANIDAD: Orden, de 3 de diciembre de 1938, restableciendo la Sección de Archivos Bibliotecarios y Museos, que tendrá las mismas funciones y atribuciones que anteriormente tuvo asignadas por el R.D. de 13 de septiembre de 1924. Gaceta de la República: Diario Oficial, nº 342, de 08/12/1938, pp. 992-993:

Siglas de los archivos consultados:

ACSIC. UAYD (Consejo Superior de Investigaciones Científicas. Unidad de Archivo y Documentación).

AGA (Archivo General de la Administración).

AFMA (Archivo de la Fundación Max Aub de Segorbe).

AJAE (Archivo de la Junta de Ampliación de Estudios e Investigaciones Científicas).

AMO. LJGS (Archivo Municipal de Orihuela. Legado Justo García Soriano).

APR (Archivo del Palacio Real de Madrid).

AUCM (Archivo Central de la Universidad Complutense de Madrid).

CDMH (Centro Documental de la Memoria Histórica de Salamanca). 